\title{
Beyond traditional ethics when developing assistive technology for and with Deaf people in developing regions
}

William D. Tucker

\section{Overview}

There are limitations to traditional ethical approaches and procedures when engaged in assistive technology (AT) research for Deaf people in a developing region. Non-traditional issues arise as a consequence of employing action research, including but not limited to how informed consent is construed and obtained; empowerment of participants to become involved in co-design; awareness of unfamiliar cultural issues of participants (as opposed to subjects); and accommodating community-centred, as opposed to person-centred, nuances. This chapter describes AT research with an entity called Deaf Community of Cape Town (DCCT), a disabled people's organisation (DPO) that works on behalf of a marginalised community of under-educated, under-employed and semi- literate Deaf people across metropolitan Cape Town. We describe how non- traditional ethical concerns arose in our experience. We reflect on how these ethical issues affect AT design, based on long-term engagement; and summarise the themes, what we have learned and how we modified our practise, and finally, offer suggestions to others working on AT in developing regions.

\section{Introduction}

We conduct assistive technology (AT) research with and for a local Deaf community in Cape Town, South Africa. The capital 'D' calls attention to a cultural identity and a preference for using signed language to communicate, in our case South African Sign Language (SASL). Our understanding of Deaf $v s$. deaf is that deaf and hard of hearing people prefer to use the written and spoken language of the surrounding majority even when they struggle to hear, e.g. using amplification, reading lips and via text. Deaf people, on the other hand, are those who prefer to use SASL as a 'mother tongue' including hearing children of Deaf adults (CODA). Thus people can be both Deaf and/or deaf; and the cultural considerations become very interesting in developing regions.

Given this context, allow us to relay a short anecdote that serves to highlight the kind of issues we encounter that push us beyond traditional ethics concerns. 
We learned that Deaf people in the community were somewhat embarrassed by their use of text to communicate with hearing people. We also observed that they had no such inhibition texting to one another in broken and misspelled English. Since instant messaging and other forms of Internet-based texting were thousands of times cheaper than SMS (short message service), we began an informal awareness campaign to champion the use of MXit and Facebook. While the majority of the DPO staff was keen to embrace these cheap services to communicate with one another, one was adamant that neither was appropriate for Deaf people. The explanation was as follows: There was a high profile tabloid story about MXit and pornography; that MXit could be commandeered to send pornography to people. Regarding Facebook, the concern was that someone could use a PC at the DPO to say something negative about someone on Facebook and the DPO could be sued for libel because of the physical placement of the computer. Our initial reaction was that these concerns were not entirely valid since with either service, one can choose one's friends, and therefore control incoming and outgoing messages. We went ahead and encouraged the others to learn how use MXit and Facebook, and tried to inform this person that the concerns could be addressed by knowledge of how to better use the tool. We continue to try and understand where the concerns are coming from. However, many Deaf people in the community have made the plunge, especially on Facebook, where all comments are somewhat public, i.e. some felt empowered and used the services, whilst others did not and declined to do so. We must accept both ways as valid.

The anecdote brings to light several interventionist ethical issues that arise during the course of conducting action research which are not necessarily covered by traditional codes of ethics or institutional review board (IRB) type evaluation: the Deaf person's aversion to MXit and Facebook and how we nonetheless encouraged others to learn how to use those applications, and even told that reluctant person we were doing so. This is a situation that can arise in action research and interventionist information and communication technology for development (ICT4D) work that an IRB does not and cannot address. This chapter argues that these types of issues also have ramifications for technical system design.

A strong argument for ICT4D was made by Brewer et al. (2005), in particular the leveraging of Computer Science for the task (Dias and Brewer 2009). The challenges of ICT4D research are technical, environmental and cultural (Brewer et al. 2006). The non-technical aspects often tend to dominate in resource- limited environments (RLEs), particularly in low and middle income countries (LMICs), requiring the formation of multi-disciplinary teams and the deployment of mixed methods. For this reason, some may question if is it even computer science research (Toyama and Ali 2009). Despite these disciplinary squabbles, the 'field' of ICT4D has soldiered on, amassing a convincing collection of conferences and journals that accommodate a 
continuum of contributions from both technical and social sciences. Several dominant themes have emerged. One of them is HCI (human computer interaction) for development research. Examples include Ramachandran et al. (2007), Kam et al. (2006) and Anokwa et al. (2009) who all in one way or another advocate that traditional participatory design (PD) is not sufficient where one must consider and incorporate a social context that is often alien and unfamiliar to researchers performing fieldwork in developing regions.

Information and communication technology (ICT) and AT for disability and accessibility in RLEs is a relatively small niche research area (Samant et al. 2013). Research papers on disability research in developing regions, RLEs and LMICs are extremely rare. Consider full papers in two flagship conferences on ICT for development: ICTD (International Conference on Information and Communications Technologies and Development) and DEV (Annual Symposium on Computing for Development). There have been six ICTD conferences, starting in 2006 and the last one in December 2013. Out of 115 full papers in total, only 2 concerned disability, and both were on AT for blind people (Lauwers et al. 2007, Pal et al. 2013). There have been four DEV conferences, starting in 2010 and the last one also in December 2013. Of the 68 full papers, only 2 concerned AT for disability, and both were co-authored by this chapter's author (Tucker and Blake 2010; Motlhabi et al. 2013b). Outside of these conferences, ICT research with and/or for Deaf people in developing regions appears to be quite scarce. Notable examples include a comparison that identified a huge gap in ICT usage between deaf people in developed and developing regions (Agboola and Lee 2000); DeVelle's (2011) short paper on mobile devices for Deaf people; and Mbulamwana's (2011) short and contradictory discussion about the merits of SMS while noting that $80 \%$ of Deaf Ugandans are illiterate and their English skills are therefore very low. Then there are numerous outputs by members of our research team, including but not limited to: Glaser (2000), Glaser and Aarons (2002), Glaser, Young \& Porteous (2005), Zulu, Le Roux and Glaser (2005), Glaser and Lorenzo (2006), Mutemwa and Tucker (2010), Blake et al. (2011), Chininthorn et al. (2012), Henney and Tucker (2013); and Motlhabi et al. (2013a, 2013b). We feel we have much experience in this niche area, especially concerning Southern Africa, with developing regions that are not unlike many others across the globe, although they retain notably African characteristics, such as 'ubuntu' (see Section 2.5 below).

Many researchers in the ICT4D realm work within an action research paradigm, with explicit goals of socio-economic development and empowerment via interventionist and transformative participation. Action research is essentially a post-positivist approach that is criticized by positivist scientists for being nonreplicable, un-objective and non-scientific. However, the scientific basis of action research has been argued by Susman and Evered (1978) and Checkland and Holwell (1998), and many practitioners in the fields of Information Systems and 
ICT4D adhere to action research tenets. At its heart, action research concerns leveraging research for empowerment, emanating from a Scandinavian tradition of worker empowerment (Stringer 1997, Carr and Kemmis 1991). A major challenge of action research is to achieve both community empowerment and academic research outputs. McKay and Marshall (2001) called this the 'dual imperative'; which manifests a tension between praxis and theory.

There are many forms, or interpretations, of action research. Participatory action research emphasises, as its name suggests, participation with end users (Kemmis and McTaggart 2000). Action research is compatible with development studies, and ethnographic action research in particular (Tacchi et al 2003). Sterling and Rangaswamy (2010) discuss how action research in development brings challenges to IRBs, particularly for informed consent, and this topic will be addressed in more detail below. Dearden and Rizvi (2008) discuss action research and related methods from two different perspectives: participatory interactive systems design and participatory approaches to international development. Following on this, Dearden (2013) discusses action research as a mechanism to conduct interventionist work. Action research has also been championed in ICT4D work by Tucker and Blake (2010) and Doerflinger and Dearden (2013). Action research has only recently been embraced in the field of contemporary HCI, an area of Computer Science that has long resisted the non- positivist leanings of action research, e.g. Hayes $(2011,2012)$ who stresses the social intricacies and relevance of $\mathrm{HCI}$ research via engagement with end users.

Social relevance is a key driver for development studies, including ICT4D, and a main component to achieve that is participation. Both Dearden and Rizvi (2008) and Anokwa et al. (2009) survey the ICT4D reporting on participation. Anokwa et al. (2009) et al. argue that participation happens over a continuum from weak to strong. In weak participation, the participant is merely an advisor rather than a co-instigator or designer. For example, participants provide feedback on a prototype as opposed to helping design it. Strong participation, on the other hand, is a project driven primarily by a given community. There are many cases where participative reality differs from intention. Anokwa et al. (2009) derived the weak-strong take on participation from Michener (1998), who comes from a development studies perspective and examined a case study in Burkina Faso in terms of several categorisations of participation. We have taken the liberty of organising two of these categorisation schemes on a continuum, together with Anokwa et al.'s (2009) (see Figure 1), because we feel it is possible to position, and indeed to move, an ICT intervention from weak to strong participation in a developing region context. 


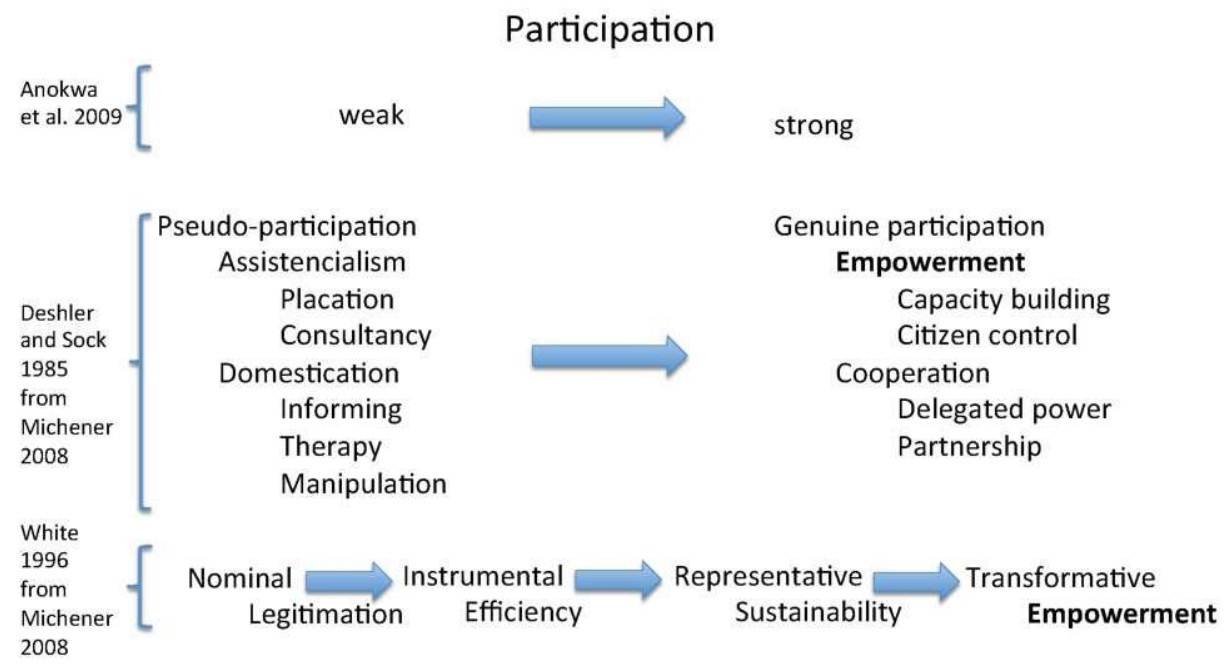

\section{Figure 1 From weak toward strong participation, emphasising empowerment.}

The end goal is empowerment of the community whereby they can drive and take on the initiative by themselves (in other words, we research ourselves out of a job). What Michener (2008) intends, however, is that despite empowerment being the end goal, "Development planners and academics are at a point where they must adjust participatory frameworks to be more responsive to field-level realities." Heeks $(1999,2002)$ and Dearden and Rizvi (2008) would agree: there is often a design-reality gap, or participation-reality gap where participation is not fully realised.

We argue that community-based co-design (CBCD, see Blake et al. 2011), our take on action research, can provide ways of bridging that gap. 'Community- based' conveys the fact that we deal with groups of people rather than individuals. In the developed world computers are geared to an individual's requirements, i.e. PC stands for Personal Computer, that a given device is meant for a single person. In many of the communities in Africa, devices, even cell phones, are shared, and possess communal properties, e.g. in hearing communities it is common to play music loudly on a cell phone to share with others. 'Co-design' derives from the application of the action research paradigm in a design setting: both the computer experts and the community members are designers on an equal footing and work cooperatively. Of course, this is an ideal approach, and the reality of performing co-design is fraught with challenges, as will be discussed below. Being based in academia, we are also involved with conveying this methodology, stressing its rewards and obstacles, to students (Blake and Glaser 2013, Blake et al. 2014). Of particular concern in this chapter are the ethical issues that arise when conducting CBCD. This entails addressing standard IRB concerns, and the consequences of performing CBCD that takes ethics concerns beyond the traditional. 


\section{Traditional ethics and limitations}

Before delving into the ethical peculiarities of interventionist research, such as alternative views of informed consent and community rather than individualorientation, this chapter first reviews the basics of conventional codes of conduct prevalent in computing-related professional bodies and also for academic research in tertiary institutions. Then the chapter explores related literature and work that both criticises traditional approaches and/or offers extensions to the traditional canon in order to deal with the consequences of conducting community-based and driven interventions.

The computing disciplines offer a collection of professional codes of ethics. The Association of Computing Machinery (ACM) and Institute of Electronic and Electrical Engineers Computer Society (IEEE-CS) have a joint software engineering code of ethics and professional practice that prescribes how to make software development "a beneficial and respected profession" (ACM/IEEE-CS 1999). This code covers eight principles: public interest, the interests of client and employer, product standard, professional judgement, management of the software development life cycle, profession reputation, concern for colleagues in the field and lifelong learning for practitioners. This code of ethics is similar to that of the British Computer Society (BCS) which has fewer but similarly worded categories including public interest, professional competence and integrity, duty to relevant authority, and duty to the profession (BCS 2011).

These two, and others, are covered by Bott (2005) whose chapter headings give an indication of where the ethical concerns are situated: e.g. law and government, nature of a profession, professional bodies in computing, what is an organisation, financing a start-up company, management accounting, investment and appraisal. Therein are codes of ethics for professional services and societies that are related yet different from codes of ethics for academic research. The former pertain to business issues, the latter mostly to medical research, although primary data collection from human interviews, surveys and the like is also included. It is notable that these codes of ethics focus on how research is carried out, yet not whether it should be carried out. The same distinction often holds for academic research codes.

In computing academia, researchers are governed by both types of codes, yet research projects requiring ethics approval are ultimately approved by an IRB based on research-oriented rather than professional ethics, i.e. on the rights of the subject rather than on how professional responsibilities are carried out. This subject-orientation is interesting because a) an IRB does not necessarily decide whether research should be pursued or not; just that it is done correctly; b) an IRB typically does not deal with technology research, if humans are not (directly) involved; and c) an IRB tends to be concerned with a human as opposed to the community in which that human may inhabit (we come back to this last point again several times below). Because of the human orientation, though, research codes of 
ethics mainstays include voluntary informed consent, right to withdraw, and avoiding deception. The Singapore Statement on Research Integrity ( et al. 2010) is a high level "global guide to the responsible conduct of research" that states five basic ethical principles which are similar to the professional codes: honesty, accountability, professional courtesy and fairness, and good stewardship; but then moves on to clarify these in terms of research activities, e.g. research methods, research findings, authorship, publication acknowledgement, peer review and conflict of interest. The Singapore Statement intends support from "appropriate national bodies and organisations" (Steneck et al. 2010). These are most likely based or at least linked to a clinical and/or medical code of ethics, e.g. Emanuel et al.'s (2000) highly cited "What Makes Clinical Research Ethical?". For example, in South Africa, the local ethics guidelines are issued by the South African Medical Review Council (MRC 2006). Therefore, when an academic research project is deemed to have ethical concerns, the principal investigator must secure ethics permission or certification from an IRB.

For the most part, traditional ethics codes, both professional and academic, are sufficient to govern the IRB gatekeeping process; although that gatekeeping can also exclude research that is controversial either politically, or because it challenges paradigms. Nonetheless, limitations of applying traditional ethics codes can appear, especially in technical scientific disciplines when non- traditional research methods are chosen, e.g. action research or CBCD. This is not to say that these established codes are not relevant. Their concerns must be addressed. However, some aspects can be lacking in applicability and/or relevance to interventionist and transformative participatory research. In addition, the IRB as gatekeeper raises the issue of the responsibility to exclude research that has negative impact on 'subjects' or other aspects, such as the subject's community, as is often the case with interventionist methods. While medical-oriented ethical concerns tend to focus on the subject, usually an individual, Emanuel et al. (2004) extend that further to address the subject's community and possibly an entire community itself. Emanuel et al. (2004) also question whether it is ethical or not to pursue a given research agenda, in addition to stipulating guidelines about how to conduct the research.

\subsection{Socio-cultural assumptions}

A first concern with intervention-driven research is that traditional and established codes of ethics are only partially applicable to work in developing regions. In our view, these codes can be written with assumptions about end users and their environments, and can also be read with similar tacit assumptions. For example, the ACM/IEEE-CS code is oriented from and toward the developed world, or global North. It is not that this code of conduct does not address ICT4D issues. It is more that the education and practice of Western- schooled technical researchers do not necessarily give consideration to sensitive and non-tacit social and cultural aspects of development issues. These issues can lead to the 'design-reality gap' 
(Heeks 2002), where a researcher's tacit cultural assumptions can cause disconnect between perceived and actual user needs. This can result in a 'partial failure' or 'white elephant'. The 'tyranny of participation' (Heeks 1999) is another manifestation of disconnect where a researcher may feel that methods employed are participatory yet the reality may be very different due to power relations (Michener 1998). Cultural assumptions come with neo-colonialism even, and especially, if unintended. These issues are well known traps that can be difficult to grasp by the unaware or unprepared researcher. This applies to both novice and experienced researchers, especially those schooled in the global North conducting research in the global South, or even those schooled in the global South in North-styled institutions.

\subsection{Dynamic and community-driven research agenda}

A second concern for applying traditional research ethics to ICT4D projects, especially interventionist action research projects, is that an ethics approval by an IRB is not flexible for on-going negotiation, e.g. changing of research goal posts based on input and direction from a participating community (Sterling and Rangaswamy 2010). This issue is also noted by Emanuel et al.'s (2004) revision of their original document (Emanuel et al. 2000) to specifically address clinical research in developing regions, especially along the theme of the negotiation between stakeholders; which serves as the main reason for their revision. In some communities, decisions on participation and who participates and how, may be made by the community and/or its elders or traditional leadership. This can be counter to formal and bureaucratic IRB ethics processes, and may or may not be appropriate for a community. One can envisage a scenario where the ethics processes are governed by the community rather than an IRB. On the other hand, not everyone, possibly even the researchers, must blindly adhere to the values of a given community; although those values must still be respected. A situation can also be envisaged whereby people are pushed by their own community into being participants; and they might not accept that way of decision-making (see Kaplan 1996 for some interesting examples of this in rural South Africa). Another way of looking at it is that IRB-orientation imposes a fixed process upon the iterative and evolving cycles of research as prescribed by interventionist action research. The terrain is fraught with permutations, from all sides: the researcher, community members, informal and formal leadership, and government. The point here is that community-driven research agendas can change in unexpected ways.

\subsection{Informed consent}

A third concern is how informed consent is explained and recorded. An IRB requires a research (team) to define informed consent issues up front and have participants acknowledge these up front, too, in writing. Sterling and Rangaswamy (2010) are particularly critical of this traditional notion of both proscribing and recording informed consent because of how a) stakeholder relations change over 
time and b) traditional informed consent can harm community involvement and trust of community (for the researchers) simply due to its alienating mechanisms such as signing official forms that participants may not fully comprehend, e.g. if they are Deaf and possess limited text literacy, or putting an ' $\mathrm{X}$ ' when participants cannot write. Sterling and Rangaswamy (2010) make suggestions such as not using pen and paper to collect informed consent signatures, e.g. recording oral consent or video recording signed language consent along with explanation of the consent form in signed language. Emanuel et al. (2004) would agree, stating that "researchers should use consent procedures that are acceptable within the local community". Emanuel et al. (2004) go further on the topic of informed consent to recommend that "the local community should help to establish recruitment procedures and incentives for participants", "disclosure of information should be sensitive to the local context", "'spheres of consent', ranging from village elders to leaders ... may be required before researchers can invite individual participation" and "special attention must be given to ensure that individuals are aware of their right to and actually are free to refuse to participate". Thus, informed consent is itself a concept arising out of a particular cultural context; and may not be relevant in other cultural contexts. What may be useful, then, is an ethical approval and overview process defined in the local community by the people being researched; such that issues of concern to a particular community are raised.

\subsection{Informed participation}

For another perspective on informed consent, consider the notion of informed participation, which can be considered complementary to informed consent (Hersh and Tucker 2005). Informed consent refers to an acknowledgement of the ramifications of participation in a given research project, yet not necessarily being privy or even involved with its formulation and execution. Informed participation, according to Hersh and Tucker (2005), is conceived such that in order to achieve true action research, the research agenda must be open from the start, with no hidden motives or objectives hidden behind clever data collection. Several well-known examples, such as the Milgram experiment, are described by Hersh and Tucker (2005) to demonstrate that some research should not be granted permission to be carried out in the first place (again, an issue that an IRB does not contend with for myriad reasons, e.g. political). The assertion is that "ethical behaviour is a pre-requisite for obtaining meaningful results", and that informed participation, in addition to informed consent, is fundamental to achieving ethical behaviour. Going beyond this initial basis of 'no hidden agendas' for informed participation, this chapter argues that one way to do this effectively is to enact community engagement in the conception of and strategy for the research project before the process even begins. Thus the community also helps to define the concerns of the informed consent process itself, rather than 'putting the cart before the horse', or in this case, the consent form before actually engaging community members. Traditional processes, including those frequently governed by IRB, fail 
to address this, as an IRB expects researchers to define an information sheet and consent form so that participants can grant permission for a pre-defined research process before it begins. With community-based co-design and other forms of action research, the research agenda and process are constantly evolving based on the consequences of continual engagement between stakeholders, and can indeed be initiated by and with participants.

\subsection{Beyond traditional ethics}

These concerns move the discussion beyond traditional ethics procedures and concerns. All of the above involve aspects of conducting scientific research, be it positivist or post-positivist, or some combination, that are peculiar to technology research interventions in developing regions. For example, Dearden (2013) discusses the ethical tension between "detached enquiry" and "help". These differences cause us to critically question our understanding of the role of researchers. For example, to what extent should researchers get involved or distance themselves? Help and involvement also raise ethical issues related to who sets the agenda, power and control, as well as the possibility of dependence upon researchers and their funding, and additional questions of researchers imposing their views and/or providing assistance that is not required and/or appropriate.

There are many other questions that arise as a consequence of conducting research in developing regions. For example, what constitutes fair subject selection and even selection of entire study populations? Another overriding concern is how to make unaffordable solutions more affordable. Affordability is not something that is fixed; it is affected by inequality due to socio-economics (see Bhutta 2002), and also gender concerns such as patriarchy. Consider how political issues and power dynamics can also affect affordability -not only in the technology arena, e.g. communications cartels. Consider HIV drugs that are deliberately kept expensive by large pharmaceutical firms that do not like the fact that African countries can produce their own much more cheaply. None of these issues are easily addressed or static; and any or all can be changed. Many such issues are addressed by bridges.org's Real Access/Real Impact criteria (see see Tucker and Blake 2010 because the bridges.org website is now defunct). There is also the balance between person and community - this is different in different cultures, e.g. in Africa, one interpretation of the concept of 'ubuntu' is that it can mean that an individual is defined by membership in a community, which is very different from the Western 'looking glass self'. In Africa, shared devices such as mobile phones, are quite common. And in Africa particularly, researchers and practitioners often innovate to deal with frequent power outages and very expensive communication costs.

Because of practical, socio-economic and cultural issues, particularly the community orientation, Averweg and O'Donnell (2007) saw the need to define and classify the ethics peculiar to development informatics, similar to how Emanuel et 
al. (2004) modified their previously developed world orientation from Emanuel et al. (2000). Efforts to widen the scope of clinical research ethics for the context of RLEs in developing regions and LMICs is the topic of the next section.

\section{Ethical frameworks for developing regions}

As pointed out by Dearden's (2013) survey of ethics in the ICT4D literature, there is a dire lack of research publications with respect to ethics in ICTD/ICT4 ${ }^{1}$ literature. This section briefly covers some examples that contribute to this small niche area. Even amongst that literature, there are, in our opinion, too few pertaining to Deaf or AT studies in developing regions.

Emanuel et al. (2004) adapted their highly referenced standard of Emanuel et al. (2000) to include items and extensions specifically for clinical research in developing regions. The shifts are notable in the recognition of collaboration via communities and social relationships; clearly beyond the scope of subject- oriented IRB processes. Examples of the changes include the addition of collaborative partnerships, value came to emphasise social value, fair subject selection become fair selection of study population, and respect for enrolled subjects became respect for recruited participants and study communities. This reworked framework explicitly recognizes that researchers are coming from very different backgrounds and perspectives from the developing regions in which the work is being done. In addition to "explicating a previously implicit requirement for collaboration", the 2004 version also provides a set of "specific and practical benchmarks to guide researchers and research-ethics committees in assessing how well the enumerated ethical principles have been fulfilled in particular cases" (Emanuel et al. 2004). Their goal for the social reorientation and the benchmarks is to minimize exploitation in developing regions, by adding additional concerns to standard IRB processes, which could lead to tensions and conflicts with those processes.

Bhutta (2002) also advocates several non-traditional points with respect to conducting health research in developing regions. Bhutta emphasises that health research ought to promote equity and local capacity building. Bhutta does not offer specific solutions; rather that health and research issues must be linked to equity, that we develop local research capacity together with capacity to determine and enforce ethical standards locally. Thus, there is a need to involve stakeholders such that ethical standards set in the North do not just necessarily get applied in the South. In other words, Bhutta (2002) is saying that research ethics mandate empowerment of participants in developing regions. This could lead to methodological tensions, especially for pure objective positivism that sees participant as subject. Bhutta asks questions such as: is it ethical to research solutions that are

\footnotetext{
${ }^{1}$ Note that in the community, there is a nuanced distinction between ICTD and ICT4D which is very effectively explained by Sterling and Rangaswamy (2010), and is considered beyond the scope of this chapter's purview.
} 
not yet affordable for a community, even though they may indeed work? Perhaps, as Buttha suggests, it is best to rather go for lower tech solutions that are affordable and still work. It is also worth noting that research can bring costs down; and furthermore, that costs can also be political, and are not absolute.

Another perspective comes from Averweg and O'Donnell (2007), who presented a draft code of ethics for community informatics researchers based on a need identified at the 2nd annual conference of the Community Informatics Research Network (CIRN) in 2005. The draft code repeatedly stresses consideration of community (in addition to individual), and was intended to evolve. It contained explicit requests and suggestions for comments, and appeared in the Journal of Community Informatics two years later. Somewhat apathetically, no one has commented on it and only two authors have cited it (according to GoogleScholar). Several years later, the journal editor repeated a plea to examine this code (Gurstein 2010), but there seems to be very little interest, as the draft code does not yet appear to have been modified. The draft code is notable for several bullet points contextualised for community-based research:

- respect for human dignity, e.g. "protect the interests of the person and community"

- subject-centred perspective, e.g. "active involvement by research participants", "researchers and research participants may not always see the harms and benefits in the same way"

- respecting vulnerable ${ }^{2}$ persons, justice and inclusiveness, e.g. "the CI [community informatics] researcher should reflect on the consequences of research engagement for all participants and attempt to alleviate potential disadvantages for any individual, category of person or community"

- ensuring appropriate use and ownership of research data, e.g. "ownership of information .. . shall vest jointly with the community" and "research protocol negotiated with the community"

\section{Experience in the field}

Keeping these issues in mind, we now turn to our experience in the field. We portray illustrative examples from our fieldwork, and tie them to both traditional and non-traditional ethical concerns as outlined above.

\subsection{Background}

According to our provincial Deaf Federation of South Africa office (DEAFSA 2014), there are approximately 1.4 million who have some degree of hearing loss, out of 55 million South Africans. Of these, roughly 600 ooo are 'profoundly Deaf'. Thus, $1 \%$

\footnotetext{
${ }^{2}$ The word 'vulnerable' is problematic; it can be used to protect or to disempower. Note 'protection' can also be problematic.
} 
Deaf and 2.5\% hard-of-hearing, of the South African population respectively. Others estimate the number of Deaf people who use SASL between 500 ooo and 1.5 million Deaf people [SignGenius, n.d.], while Druchen (2007) put the number of SASL users at one million in 2007. We can surmise that European numbers are considerably smaller.

In South Africa, as is worldwide, many literate and illiterate Deaf people prefer to communicate in their own signed language; in our case, SASL. If one takes into account general demographics from the South African census data (see www.statssa.gov.za), more than half of the population is rural and the majority are poor. These characteristics translate to the Deaf population quite literally. Deaf South Africans experience poor text literacy (in any of the eleven official South African languages) due to limited educational opportunities. However, despite poor text literacy, many South African Deaf people appear to be entirely literate in SASL. There is currently a lobby to make SASL the 12th official language of South Africa (Druchen 2007). If successful, it would oblige the government to provide full service in this language. It is believed that the expense is currently a major stumbling block to approving this officialisation.

We work with a Deaf DPO (Disabled Persons Organisation) called Deaf Community of Cape Town (DCCT, see www.dcct.org.za). Most Deaf adults associated with DCCT are semi-literate, at best (Glaser and Aarons 2002; Glaser and Lorenzo 2006). Many are unemployed, but those who are employed are often under-employed in menial jobs. This adversely affects the socio-economic level of the community as a whole. The Deaf Community is underdeveloped in terms of ICT access and participation (Glaser 2000; Glaser and Tucker 2004). Recognizing these gaps, grassroots DPOs, such as DCCT, have arisen to take action on their community's behalf. There are not enough of these DPOs, and they themselves are resource-constrained. DCCT is staffed almost entirely by Deaf people and serves the needs of a large Deaf community in the province. It was founded by members of the community in response to a dearth of services and support from mainstream and official sources.

Factors that characterize the Deaf Community's ICT ecosystem include: very expensive Internet, fixed and mobile communication costs 3 , no commercial relay services; and even if a video relay service (VRS) were available it would be prohibitively expensive. Civic engagement is difficult when police, doctors, and government officials, for example, are unable to converse in SASL; and

\footnotetext{
${ }^{3}$ Note that according to the International Telecommunications Union (ITU, see www.itu.int), this applies across the board to everyone in South Africa - that prices here are more in line with developed countries in the global North rather than with countries like India, Sri Lanka, Senegal and Brazil. Therefore, the use of standard communication services is prohibitively expensive for all poor South Africans.
} 
interpreters are rare 4 , expensive and beyond the reach of most Deaf people (rates start at R350 per/hour, currently about £20). We cannot possibly address all of these issues with our research programme, so we start by addressing needs prioritized by DCCT where we have expertise, such as designing appropriate and accessible AT and building ICT capacity.

Academic researchers from Computer Science departments at two local universities, University of the Western Cape (UWC) and the University of Cape Town (UCT) have been involved for many years with DCCT. Our initial intent was to support remote communication between Deaf people and hearing people, e.g. voice relay with instant messaging (Glaser and Tucker 2004; Yi and Tucker 2009); between Deaf people, e.g. with PC-based video (Ma and Tucker 2008, Ramuhaheli 2011) and mobile-based video (Wang and Tucker 2010, Erasmus 2012); and then, with collaboration from Industrial Design Engineering at Delft University of Technology (TU Delft), from Deaf people to officialdom, e.g. with a doctor (Looijesteijn 2009) and pharmacist (Chininthorn et al. 2012; Mothabi et al. 2013a, 2013b).

While the technical goals of these research projects have been achieved to a certain extent, of equal interest has been the way the research-provided computer systems have been appropriated, in a positive sense, by the Deaf community for other purposes. This relates to the unexpected uptake in the use of the computers for general access to information and social networking, e.g., the prolific use of Facebook. Included in these spin-off uses was the demand by the community for the training of Deaf people in ICT literacy. We facilitated this by the introduction of the internationally accredited ICDL programme 5 which recently saw three Deaf people at DCCT receive eLearner certificates (see Figure 2). While three appears a small number, we are not aware of anyone associated with DCCT, with approximately 2000 members, possessing even a high school matriculation (diploma). Thus, this accomplishment truly stands out (and all three granted permission to use this photo). In addition a Deaf person was trained to maintain the computers at the DPO. Our research efforts provided access to hardware, software and network ${ }^{6}$ and over time the system has been adapted for advocacy and empowerment. A clear mandate of engaging the Deaf community at all stages in the research process, as defined by action research and community-based co-design (see Section 6) is the role for researchers to educate communities on the possibilities of technology. Otherwise communities are not in a position to set the agenda and decide what technologies they want, as they do not know what is available. By engaging with communities in this manner, they become empowered

\footnotetext{
${ }^{4}$ There are only 84 SASL interpreters on the DEAFSA registry in the entire country, of which 43 have no formal training, 31 with 240 study hours of training and 10 with a further 480 study hours; and only 7 of the total of 84 are actually accredited by DEAFSA; and only 19 of the 84 are resident in the Western Cape province where DCCT is based. ${ }^{5}$ ICDL (International Computer Drivers License), www.icdl.org.za, is an internationally recognized computer skills certification programme run by the (European) ECDL foundation (www.ecdl.com).

${ }^{6}$ The network costs are now being borne by the community itself.
} 
to enact these activities in an informed way. The remaining subsections call out various aspects of our experience while doing this together with the Deaf community.

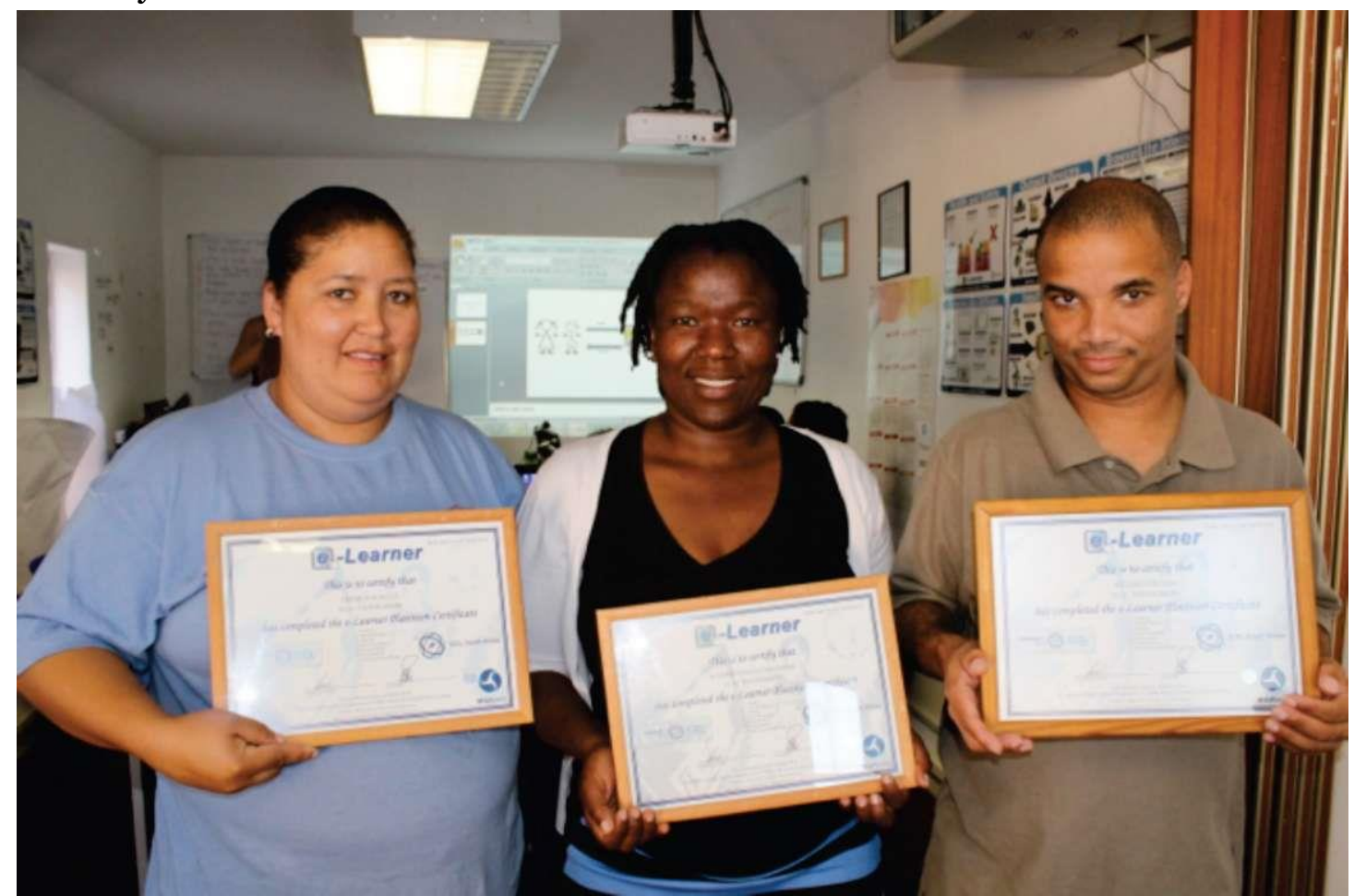

Figure 2 Several DCCT staff members received e-Learner certificates from ICDL.

\subsection{Timing}

The initial phase of the ICT interventions dealt with a variety of text relay systems. The first to be trialled with a Deaf user revealed that Deaf people were very self-conscious about their typewritten text (Tucker et al. 2003). A later iteration, called SIMBA (Sun and Tucker 2004), was installed at DCCT's PC lab. This lab was funded by industry and governmental research donors. The ethical issues of such funding in terms of control have been minimal as our funders allow DCCT and us to drive the research agenda independently. On the other hand, the nature of the business practices deployed in order to provide such 'social responsibility' funding could raise additional ethical questions.

Regardless, the funding was provided for the purpose of introducing and trialling alternative and exploratory ICT interventions. Along with members of DCCT, we identified Thursday afternoons as a good time to trial the instant messaging (IM) and SMS-based text relay. We ran into the problem that actually, the Deaf people could not call anyone since the people they wanted to call were working and could not take calls. Travel to and from DCCT was also problematic (see Section 4.8). This highlights issues covered by Section 2.1. 


\subsection{Setting the research agenda}

This section highlights issues covered by Section 2.2. In truth, the Deaf community did not ask for the text relay phase of projects, or any of our projects up until SignSupport. The ICT interventions, and the research funding, started because of a perceived overlap between Voice over Internet Prototol (VoIP) research and the Teldem, a locally produced text telephone, both of interest to the primary donor, Telkom. We perceived the need for such technology and proceeded with a series of projects that ultimately ended up unused. However, the requirements for the SignSupport project, a mobile tool to assist communication between a Deaf person and a medical doctor, were initiated from DCCT participants (Looitjesteijn 2009). This project was further refined by Chininthorn et al. (2012) to focus on a more limited communication domain, with a pharmacist.

Because of the long running nature of the wider project on AT with and for this Deaf community since 2001, we are able to devise a number of future work ideas each year, and are able to take in new postgraduate students each year to continue work on the project. However, even with the underlying requirements set by the Deaf community, we still encounter the dilemma of whether each particular project is acceptable by the community or not. For example, we know by interviewing both Deaf and pharmacist participants after a mock trial that SignSupport may indeed require a VRS when the pre-recorded dialogue on the phone is unclear or insufficient to convey critical communication. Thus we enlisted a PhD student to include the relay work and mobile video work we had done with earlier projects. His particular spin, though, for a research topic was to secure the relayed communication. So, the need for mobile relay has emerged from participants, and not the security aspect of it. Is it right to pursue security as a priority when it was not identified as such by the Deaf community? We are working under the premise that by educating Deaf people about Internet and mobile security there might be a good offshoot of the technical development. But then, the Deaf community had not asked for such instruction either. We therefore view part of the research programme to empower our Deaf partners to be able to participate more strongly, e.g. with English and computer literacy training and accreditation. With regards to this particular decision, we have decided to continue with the project because a video relay service was prioritised by the community, and the security aspect provides both community empowerment and Computer Science research merit, illustrating a parallel research agenda that aims to satisfy and empower both major stakeholders.

Consider another example illustrating a similar decision. A postgraduate student had modified a pattern passcode for SignSupport as a final year project. The pattern passcode enhancement was identified by observing that Deaf trainees for the ICDL course routinely forgot text-based passwords. We thought that a more visual passcode, more similar to the visual nature of signed language, would be more appropriate for them. However, the Deaf users had not explicitly asked for 
this, perhaps because they did not possess enough computer literacy to warrant offering such a modification. When the pattern passcode was shown to Deaf people, we received encouraging feedback. This particular student wanted to continue with the project for an MSc, yet we convinced him to switch to a project more prioritised by the Deaf community: to enable SignSupport for other scenarios, as multiple scenarios were identified by Looijesteijn (2009). Then it becomes our challenge, as computer scientists based at a tertiary institution, to devise a research topic out of needs prioritised by the Deaf community, and to recognise and accommodate that their priorities can and do change. We achieve this by engagement and awareness activities, both formal, e.g. workshops and informal, e.g. regular weekly visits.

\subsection{Informed consent}

We experienced problems with getting consent form signed as prescribed by the UWC ethics committee. The consent forms were alienating, incomprehensible and were full of 'legalese'. They were accompanied by a full-page information sheet describing the project. Even when first translated into SASL by an interpreter, the Deaf participant typically took the sheets home. It was very difficult to retrieve them signed. By the time of Mutemwa et al.'s work (2010), we rendered the information sheet and consent form in point form and translated each point into SASL. This was a huge improvement in terms of Deaf participant understanding, and consent was collected visually with video recording and was much more natural for them. This illustrates how such problems, as identified by Sterling and Rangaswamy (2010), can be easily overcome (see Section 2.3). In our view, informed consent forms are often about 'ticking' boxes. We take the position that participants should have relevant information, communicated to them in their preferred language, in order to ensure that they do not feel they are being exploited.

\subsection{Satisficing feedback}

Our method of ICT development is based on cycles of training, intervention, collecting feedback and reflection. The collection of objective and useful feedback remains problematic as one can safely assume that participants will satisfice answers, i.e. tell the researchers what they think the researcher wants to hear (related to issues covered in Section 2.1). There are ways to triangulate data to identify satisficing, e.g. we can instrument software to collect usage or performance metrics and then compare that data to answers collected with questionnaires, structured interviews and focus groups.

During the most recent round of feedback collection on the SignSupport app at a mock pharmacy, no actual medication was dispensed or used by Deaf patients. Does this have an effect on the objectivity and completeness of the feedback voiced by Deaf and pharmacist participants? This is not easy to address. 
This brings up the question: is feedback on prototypes enough to drive a project forward, e.g. SignSupport? While some participants voiced some concerns, the results of feedback from the latest SignSupport trial in a mock pharmacy (Motlhabi et al. 2013b) indicates that SignSupport should be trialled next at an actual pharmacy. To some, this may be construed as weak participation (see Section 2.2 and Figure 1). Even though together with the Deaf community we envisioned how SignSupport could become a tool of empowerment, at this stage, we are still in feedback mode. The transition to empowerment will only come when the research project moves out of the mock pharmacy into an actual pharmacy, and from there into some sort of sustainable, if not commercial, operation.

One way we have identified to help 'spread the word' more widely is to also move from dealing only with DCCT staff to the wider Deaf community. Fortunately for us, this community meets on a monthly basis, on the 3rd Sunday of each month, and we can tap into this for a) data collection and b) publicity of the ICT that is available to the community. After tapping into the 3rd Sundays several times, however, we have had to withdraw because DCCT staff recently informed us that that Deaf people prefer not to have data collection activities during that time because their main purpose to attend 3rd Sunday is social. The DPO staff recommended we rather perform data collection on a Saturday, and also pay for transport to and from the centre (see Section 4.8 below).

\subsection{Creating expectations}

Because of the useful and innovative nature of our work, we are often approached to disseminate our work more widely than customary academic venues. We now feel we can only bring attention to the wider community of a particular intervention when it can actually be used by them. We made the mistake of creating false expectations in the early days of the text relay phase. We had developed a prototype in the lab that worked one way between a Teldem text telephone and a telephone, i.e. it converted text to speech with Festival, an open source text to speech engine. We had published a paper (Penton et al. 2002) and received attention from the media. There was a magazine article, an online report and several radio interviews. However, the fallout was that the public exposure generated false expectations for a marginalised Deaf people who wanted to use our work right there, right now. A university will often exercise pressure to highlight community-engaged research projects publicly, and possibly prematurely. We recently declined to do this with the SignSupport project based on previous experience with the automated relay; and turned down offers for newspaper and magazine articles, and radio and television interviews. However, we did allow 'public' notice on the university website where our project can be portrayed as research and not a commercially available product. The current thinking is that we can go public after SignSupport for the pharmacy context has been trialled at an actual hospital pharmacy with real users and drugs. In reality, we should only do so when we have a mechanism online to allow Deaf people to download, install and use the application. 


\subsection{Challenging the status quo}

As the anecdote at the start of this chapter highlighted, a consequence of action research can entail challenging the status quo, especially if people, e.g. elders, self-appoint themselves as gatekeepers (or indeed as roadblocks). We kept encouraging staff members to use Facebook and MXit despite disapproval from some of the DPO staff. Facebook can make communication in text for Deaf people problematic, considering the attendant problems of literacy and even online etiquette. There are also complicated privacy concerns, especially with Facebook, and we can understand the objecting viewpoint to some extent. Yet the anecdote shows a) how we can intervene to effect social change and b) empower the community to make more informed decisions on their own by increasing ICT capacity, e.g. whether or not, and even how to use something like Facebook. It is not that we tell people to use Facebook but rather that we educate them on the advantages, disadvantages and more importantly the security concerns of any given social media application. In fact, based on casual observation (being Facebook friends with various DCCT staff members), Facebook has become an outlet for increased English text literacy, and demonstrates these people's aspirations and goals to fully participate and engage with a hearing, and often text-based, world.

A related issue is embarrassment from poor text literacy, e.g. mobile texting to hearing users. We encountered this very early with text relay (Tucker et al. 2003) yet we persisted with automatic text recognition and generation for several years until video prototypes commenced with Tucker and Ma's work $(2007,2008)$. We have noticed how the embarrassment of Deaf users that we have engaged with has changed as DCCT staff progress with English literacy, e.g. compare someone's emails, or Facebook posts from even two years ago and today. It is remarkable, albeit subjectively, how much progress they have made in terms of English fluency and confidence with increased use of text within social media.

\subsection{Participant remuneration}

An on-going dilemma is how to remunerate extremely poor participants for feedback and data collection exercises. The two local universities have different approaches: UWC gives food and UCT pays attendees cash. At UWC, we recently opted to provide money to enable people to attend a data collection section. Many of our participants can barely afford the bus, train or taxi fare to get to DCCT premises. Money was given up front, but many attendees simply did not attend. Providing money after the session is a problem, since participants can legitimately ask "How can I attend if I don't have the train fare?". We have recently changed the UWC remuneration protocol to use food vouchers at local grocery stores instead of cash, unless of course, DCCT is already providing lunch, e.g. on a Saturday. Another option could be mobile airtime/recharge vouchers (but there are four dominant mobile providers). This change in remuneration has proven successful 
for several weeks, and the issue of travel fare has lost significance because a) the Deaf people surely know that the pay-up-front was a failure and b) we can only hope that the allure of participation in the project is seen as a vehicle towards improved quality of life, i.e. the message getting around that something interesting is happening at these sessions.

On another level of participation, we employ Deaf research assistants to help manage the DCCT PC lab and collect data. These people have no formal training, and none of them have even graduated from high school. These people are often doing part-time work elsewhere. Instead of setting an hourly, weekly or monthly rate ourselves, we consult with the DCCT leaders to set pay scales to be in line with their other jobs, because our assistants only work for us part-time. We adhere to their recommendations.

\subsection{SASL interpretation}

Even though postgraduate students and their supervisors take at least a basic introduction to SASL class, we rely on professional SASL interpreters for all data gathering sessions. However, many times when we visit, both formally and informally, with the Deaf Community, we often request and/or rely on informal interpretation. We rely on informal interpretation sometimes due to budget constraints, yet more often because we make weekly visits. The latter is categorically different from traditional data collection exercises because weekly visits stimulate spontaneous forms of relationship building and reflect the dynamic nature of the project. This is simply because we need to communicate and at DCCT's premises or at one of their functions, there will usually be someone who can interpret, although they might not be an official interpreter. At times, however, an informal interpreter can get uncomfortable with a given situation, e.g. when he or she feels we should hire a professional interpreter. There are few professional interpreters, as noted above; and in the past few years, we could call upon four experienced interpreters associated with DCCT, but they are very expensive. At least with basic SASL training, e.g. see www.sled.org.za, researchers can interact informally in the native 'tongue'. However, for data collection, a research is bound to approved methods, and Deaf people are familiar with indirect communication via an interpreter, who is bound to a code of professional conduct. Furthermore, Deaf people, at least in the community with whom we work, know and trust certain interpreters so as to not cause problems with data integrity. There is another issue that researchers new to collecting data with interpretation also need to be 'skilled up' to learn that an interpreter is not meant to facilitate.

A related issue is the use of Deaf people from the community in recorded videos for prototypes rather than filming an interpreter. The main reason to do this is because DCCT is run by Deaf people, and interpreters are not necessarily considered Deaf even though they 'speak' a signed language (recall the cultural attachments of the capital 'D'). Thus, for all recording exercises, we involve an additional person. We 
read text to an interpreter; the interpreter informs and/or clarifies what the Deaf person must sign, which could be relayed differently by the Deaf person; and finally we record the Deaf person signing what we need for the application.

\subsection{Writing about the project}

It is important to use appropriate language when reporting on studies related to disability. We now routinely follow the suggestions outlined by Cavender et al. (2014) on the ACM special interest group on access (SIGACCESS) website. For example, we write for "Deaf people" rather than for "the Deaf". We always explain what we mean by "Deaf" vs. "deaf". We try to avoid words like "target community" and "human access points" (originally defined by Chetty, Tucker and Blake 2004) because of their dehumanising connotations. The Deaf community is not a target, it is a stakeholder in the action research. Likewise, calling a person an access point, like a piece of technology, is also not copacetic.

\section{How ethical issues affect technical design}

Most if not all of these issues are dynamic and ever changing, which is part of action research. This means that roles and projects need to be continually negotiated, and necessitates continual communication between stakeholders. Many of these issues lie at the fringes or beyond the reach of conventional and traditional notions of research ethics, as in the opening sections of the chapter. An example is changing research priorities mid-stream as dictated by the Deaf community, from text to video-based. Does that mean that the ethics approval has to be changed and/or re-submitted because the media for the consent form and/or data collection has changed? Another example is challenging the elders in the Deaf community regarding Facebook. Does that warrant explicit acknowledgement in a proposal sent to an IRB, because it affects primary and secondary data collection by virtue of influencing people's behaviour. These examples highlight why traditional IRB-driven ethics considerations may even be irrelevant.

As it turns out, such issues also have ramifications for technical design and evaluation of ICT artefacts, especially the iterative engineering of prototypes. For example, we moved from text-based to signed language - based prototypes because of our evolving and deepening understanding of what Deaf people want. Most of the text prototypes, culminating with SIMBA (Softbridge Instant Messaging Bridging Architecture), went unused for a number of social rather than technical reasons. Despite this, the involvement of Deaf people led to a number of innovations. For example, when we built SIMBA, we used an 'is typing' presence indicator for the Deaf person, on an instant messaging interface, to represent when a hearing person was speaking. Because of the lag converting speech to text, and vice versa, we realised we also needed a similar 'audio is typing' interface for the hearing user, and implemented that with a musical passage. 
When we started with video prototypes, our main concern was with video codec manipulation and sign language intelligibility. However, a simple yet striking piece of feedback from Deaf participants was that they preferred to have side-by- side video (see Figure 3) instead of picture-in-a-picture, because they wanted to see themselves more clearly when signing, i.e. the sender's image is too small with picture-in-a-picture like in a Skype call. We came to this innovation because of answers to open-ended questions to Deaf participants with the use of a SASL interpreter (as noted in Ma 2009). Even though we implemented this 50-50 screen split, i.e. divide a landscape screen into two equally large areas, the idea came from Deaf people not us. This is a classic example of Deaf participants helping to drive the technical agenda as well as the research agenda. This user interface novelty was carried over onto subsequent mobile prototypes (Wang and Tucker 2010) and we intend to continue using it in the future because Deaf people came up with the idea, and they like it.

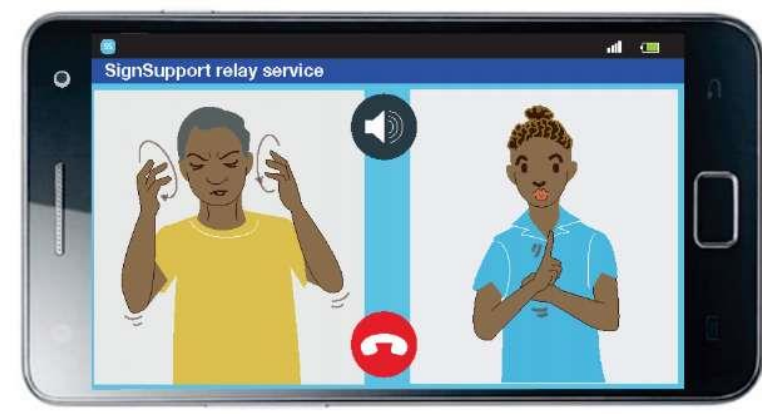

(a)

(b)

Figure 3 Side-by-side video orientation instead of picture in a picture. User (a) is the Deaf person, and user (b) is the signed language interpreter (figure adapted from Ma 2009). 
The SignSupport project was initiated on results obtained with participative generative sessions. In our opinion, the experience that DPO staff had with us during previous ICT studies, even though they were not being used, increased ICT awareness to the extent that they were able to provide more informed feedback and decisions during these sessions. This led to focussing solely on mobile devices, and also solely on SASL interfaces for Deaf end users, including visual passcodes and video reminders. This included investigation into icons meaningful to Deaf people (Chininthorn et al. 2012), and also careful attention to ensuring that recorded sign language videos said exactly what they were supposed to say, and were placed in exactly the correct places (Motlhabi et al. 2013b).

We also incorporated the code of ethics for pharmacists into the design of the SignSupport application (SAPC 2010). Integrating their code of ethics meant changing the ordering of the user interface, and introduced specific sections within the application, e.g. the background information and confirmation of identity. Details of this can be found in Motlhabi et al. 2013a and 2013b.

The eventual generality of SignSupport, in terms of scenarios, is going to support self-determination even more because the Deaf community can decide what is important to put into the application next. To do this, we are busy designing an authoring tool to help domain experts create new SignSupport scenarios. The authoring tool is an example of a technical research problem crafted by computer scientists (because this is how we think - to generalise applications for wider usage). It must be noted, however, in making this technical design decision to increase the generality of SignSupport to provide participant-driven scenarios, we are also empowering the Deaf community even more to choose and prioritise more scenarios, as well as the technical research agenda, in the future.

\section{Reflection on community-based co-design}

So how participatory are we really? Motlhabi's (2014) pyramid of weight of influence (see Figure 4) represents an ideal situation, where the most input comes from Deaf and pharmacy communities, then from a Deaf education and communication specialist, to design engineers to computer scientists who did the programming. Such participation would surely be 'strong' according to Anokwa et al. (2009), and indicate a great deal of empowerment according to Michener (2008). 


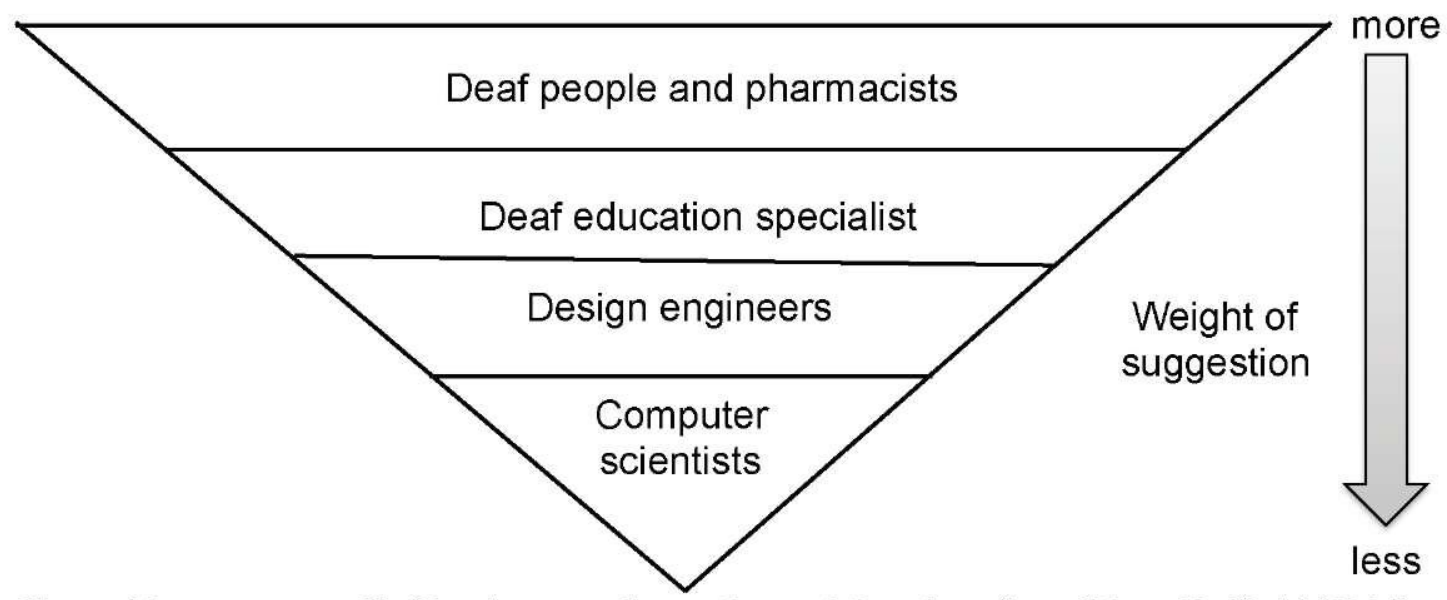

Figure 4 Inverse pyramid of involvement: fact or fantasy? Drawing adapted from Motlhabi (2014) to emphasise participation from the Deaf community.

Yet the reality is that our participatory process lies somewhere between 'weak' and 'strong' (see Figure 1), as we try to avoid the 'tyranny of participation' (Heeks 1999), as described above. We, and here we means the researchers, clearly still possess a great deal more sophistication in the ICT realm than our Deaf collaborators, and must endeavour to take actions to address this. To quote Dearden and Rizvi 2008:

"In creating a participatory approach to interactive systems design for development, it is important to recognise participation as going beyond simply engaging people as informants in design. Instead, participation must be framed as an ongoing engagement that supports learning and development of a wide range of knowledge and transferable skills. The goals of participation should be wider than the individual project and should aim for learning and long term empowerment."

The technical, and indeed socio-economic and cultural, disparity between Deaf participants and researchers will not likely change all that much despite the success of the English literacy and ICDL training. As we are mostly computer scientists and engineers pursuing technical research, we can only realistically attempt to address the technical disparity; while simultaneously attempting to minimize the power disparity by fomenting mutual respect. The Deaf participants' increased capacity enabled them to come up with the ideas for SignSupport. Further, we have learned to recognise, acknowledge and appreciate the expertise that Deaf people have with respect to how they communicate and want to communicate in signed language. We do this by pursuing the ideal of community-based co-design and engagement with them, e.g. weekly visits and interpreted data collection, both formal and informal; generative sessions and incorporating ethnographic methods into technology design and evaluation. One danger in particular for us now is that patterns of participation were originally established in weak mode, commencing with the text relay prototypes. Perhaps, as 
evidenced by the recent suggestion to conduct data collection outside of 3 rd Sundays, DCCT staff and members have internalised a particular way to deal with us. Or perhaps that is a misunderstanding - that the Deaf community wishes to separate their 3rd Sunday from the ICT project. Perhaps the case would be different if researchers possessed SASL fluency. They have rather suggested we engage larger groups of Deaf people to collect data and ideas on other days considered more convenient, and less intrusive to community goings- on.

Overall, we have seen, with the SignSupport project, that the capacity building, via formal training and also via exposure to our long term series of research interventions, the Deaf community has developed the capacity to better help drive our research agenda. We hope that those experiences are what enabled the research agenda resulting from generative sessions with key DCCT staff members; aligning research projects to a strategic trajectory. We now endeavour to develop SignSupport in a way that it can accommodate the needs defined by the Deaf community; to address multiple scenarios where the tool can provide even more communication bridges for Deaf people in their everyday lives.

\section{Conclusion}

This section summarises the main themes of this chapter, what we have learnt, how we have changed our practise, and offers advice for researchers faced with similar challenges. A danger of following a code of ethics without taking into consideration additional socio-cultural issues can entail that technical outputs of design and research may not actually address the needs of Deaf people in developing regions. We speak from experience, and learned the hard way by working with a Deaf community in a resource-limited environment for quite a number of years. It was only when we starting incorporating modifications to the standard traditional approaches that we started making more genuinely accessible and impactful innovative in-roads with respect to technical development. Therefore, in our opinion, the approach to ethics can and does have direct ramifications for technical outputs. The challenge is to adhere to ethics fundamentals while at the same time espousing a context-awareness to address and/or handle ethical situations that arise beyond the reach of traditional approaches, such as those that come from extensive, dynamic and continual interventions as is common in action research projects.

\subsection{Main themes summarized}

The main themes covered by this chapter are as follows: Tacit cultural assumptions, as opposed to cultural and value relativism (see Section 2.1), can get in the way of providing 'real access and real impact'; the community must be empowered and allowed to drive the research agenda via stronger, as opposed to weaker, participation (see Figure 1 and Section 2.2); informed consent is fraught 
with procedural challenges when dealing with communities in developing regions (see Section 2.3); informed participation should be understood, considered and pursued (see Section 2.4); and lastly, traditional ethics processes, such as those associated with an IRB, are not wrong; they just are not sufficient when pursuing AT research in developing regions (see Section 2.5).

\subsection{What we have learnt}

Based on iterative ICT interventions with a particular Deaf community since 1999, we have learnt the following: the Deaf community prefers to communicate in $S A S L$, not text, even though they also want to improve their text literacy; improved textual and ICT literacy has empowered the Deaf community to convey innovative ideas to help drive an AT research programme to mutual benefit, e.g. SignSupport; the Deaf community is a source of innovative ideas, and research projects can flow from these (postgraduate theses and publications); stronger participation, as opposed to weaker, culminates in community empowerment; and awareness of tacit cultural assumptions enables one to move beyond them.

\subsection{How we have changed our practice}

We fully understand that our lessons apply to the single case study that is portrayed in this chapter. However, the themes listed in Section 7.1 and the lessons from Section 7.2 have changed our practise, and we feel it beneficial to share how this has happened, because it has wider implications for AT design in developing regions.

We shifted from informal to formal, and certified, ICT training to build capacity with noticeable results in both communicability in written digital communication (notably email, SMS and Facebook) and input into the research programme, e.g. the mobile sign language for doctor and pharmacy scenarios. We moved from textual to SASL-based research goals and outputs/prototypes. All information relayed to the Deaf community is now in signed language, including information sheets, consent forms, questionnaires and focus group data collection exercises. We came to prioritise community-driven goals within our tertiary research programme, e.g. choosing to prioritise the authoring tool (now addressed by a team of three postgraduate students) over the 'cooler' visual password interface.

\subsection{Advice for researchers working in this domain}

Based on the above, we can therefore offer the following advice when engineering AT solutions for Deaf people in developing regions:

- Implement a certified ICT training programme, in addition to local written language literacy, alongside an AT/ICT intervention programme to empower the community to truly enact community-based co-design; such that the community can drive the research agenda. 
- Train researchers in signed language, also certified and/or accredited.

- Use professional signed language interpreters during official data collection exercises to effectively communicate with participants in their preferred language.

- Informed consent ought to be augmented by informed participation, shedding detached objectivity-styled positivism, and seen as an on-going and dynamic process.

- Become aware of, and embrace, cultural and value relativism; including but not limited to differences in individual vs. community-based orientation(s).

- A community-driven agenda, when combined with capacity building, engenders strong participation and empowerment for all stakeholders.

\section{Acknowledgements}

This chapter is dedicated to the memory of Prof. Adinda Freudenthal, who tragically passed away this year. A native of the Netherlands, Adinda was an Associate Professor of Industrial Design Engineering at TU Delft with a background in medical devices and user interfaces. Adinda became our SANPAD collaborator (South African Netherlands research Programme on Alternatives for Development - funding from the Dutch embassy, see www.sanpad.org.za). She felt a true passion for working with the Deaf community in South Africa and through supervision of two MSc research projects and a PhD, in collaboration with DCCT, UWC and UCT, sparked and guided the realisation of the SignSupport project. She is deeply missed by collaborators and beneficiaries alike.

This work would not be possible without the participation and collaboration of the Deaf Community of Cape Town (www.dect.org.za). Thanks also to collaborators Meryl Glaser and Edwin Blake; the postgraduate students involved with SignSupport: Michael Motlhabi, Prangnat Chininthorn, Mariam Parker, Sifiso Duma, George Ng'ethe, Marshalan Reddy, Muyowa Mutemwa and Koos Looijesteijn; and to all interpreters who have helped us with this project.

We also thank SANPAD for prior funding, and Telkom, Cisco, Aria Technologies and THRIP (Technology and Human Resources for Industry Partnership) for continued financial support via the Telkom Center of Excellence (CoE) programme. This work is based on the research supported in part by the National Research Foundation (NRF) of South Africa (Grant number (UID) 75191). Any opinion findings and conclusion or recommendations expressed in this material are those of the authors and therefore the NFR does not accept any liability in this regard. 


\section{References}

ACM/IEEE-CS. (1999). Software Engineering Code of Ethics and Professional Practice.

ACM/IEEECS Joint Task Force on Software Engineering Ethics and Professional Practices.

Agboola, I. O., \& Lee, A. C. (2000). Computer and Information Technology Access for Deaf Individuals in Developed and Developing Countries. Journal of Deaf Studies and Deaf Education, 5(3), 286-289.

Anokwa, Y., Smyth, T. N., Ramachandran, D., Sherwani, J., Schwartzman, Y., Luk, R., ... DeRenzi, B. (2009). Stories from the Field: Reflections on HCI4D Experiences. Information Technologies and International Development, 5(4), 101-115.

Averweg, U., \& O'Donnell, S. (2007). Code of Ethics for Community Informatics Researchers. Journal of Community Informatics, 3(1).

BCS. (2011). The BCS Code of Conduct. UK: British Computer Society.

Bhutta, Z. A. (2002). Ethics in international health research: a perspective from the developing world. Bulletin of the World Health Organization, 8o(2), 114-120.

Blake, E. H., Tucker, W. D., Glaser, M., \& Freudenthal, A. (2011). Deaf telephony: Community-based co-design. In Y. Rogers, H. Sharp, \& J. Preece (Eds.), Interaction Design: Beyond Human- Computer Interaction (3rd ed., pp. 412-413). Chichester: Wiley.

Blake, E., \& Glaser, M. (2013). Computer Science students learning co-design with a Deaf community. In C. Ohajunwa \& J. Mckenzie (Eds.), Beyond "if" to "how": disability inclusion in higher education University of Cape Town case study (Vol. 4, pp. 86-99). Disability Studies Programme, School of Health and Rehabilitation Sciences, University of Cape Town: Disability Innovations Africa.

Blake, E., Glaser, M., \& Freudenthal, A. (2014). Teaching Design for Development in Computer Science. Interactions, 21(2), 54-59.

Bott, F. (2005). Professional issues in Information Technology. Swindon: The British Computer Society.

Brewer, E., Demmer, M., Du, B., Ho, M., Kam, M., Nedevschi, S., ... Fall, K. (2005). The Case for Technology in Developing Regions. Computer, 38(6), 25-38.

Brewer, E., Demmer, M., Ho, M., Honicky, R. J., Pal, J., Plauche, M., \& Surana, S. (2006). The 
Challenges of Technology Research for Developing Regions. Pervasive Computing, 5(2), 15-23.

Carr, W., \& Kemmis, S. (1991). Becoming Critical - Education, Knowledge And Action Research. London and Philadelphia: The Falmer Press.

Cavender, A., Trewin, S., \& Hanson, V. (2014). Accessible Writing Guide. Special Interest Group on Accessibility in Computing. Retrieved March 11, 2014, from http://www.sigaccess.org/welcometo-sigaccess/resources/accessible-writing-guide/

Checkland, P., \& Holwell, S. (1998). Action Research: Its Nature and Validity. Systemic Practice and Action Research, 11(1), 9-21.

Chetty, M., Tucker, W. D., \& Blake, E. H. (2004). Developing locally relevant applications for rural areas: a South African example. In G. Marsden, P. Kotze, \& A. Adesina-Ojo (Eds.), Annual Research Conference of the South African Institute of Computer Scientists and Information Technologists (SAICSIT) (pp. 239-243). Stellenbosch; SAICSIT in association with ACM.

Chininthorn, P., Glaser, M., Freudenthal, A., \& Tucker, W. D. (2012). Mobile Communication Tools for a South African Deaf Patient in a Pharmacy Context. In P. Cunningham \& M. Cunningham (Eds.), Information Society Technologies - Africa (IST-Africa). Dar es Salaam May 9-11; Dublin: IIMC International Information Management Corporation.

DEAFSA (2014) Personal communication. Western Cape Provincial Director, Cape Town, South Africa.

Dearden, A. (2013). See No Evil ? Ethics in an Interventionist ICTD. Information Technologies and International Development, 9(2 ICTD2012 Special Issue), $1-17$.

Dearden, A., \& Rizvi, H. (2008). Participatory IT design and participatory development: a comparative review. In Tenth Anniversary Conference on Participatory Design 2008 (PDC 'o8) (pp. 81-91). Bloomington Oct 1-4; New York: ACM Press.

DeVelle, S. (n.d.). Mobile Devices as Assistive Technologies. In Mobiles for Education Alliance Series. Washington, D.C.: USAID and mEducation Alliance.

Dias, M. B., \& Brewer, E. (2009). How computer science serves the developing world. Communications of the ACM, 52(6), 74-80.

Doerflinger, J., \& Dearden, A. (2013). Evolving a Software Development Methodology for 
Commercial ICTD Projects. Information Technologies \& International Development, 9(3), 4360.

Druchen, B. (2007). Memorandum towards recognition of South African Sign Language as the 12th official language. DEAFSA.

Emanuel, E. J., Wendler, D., \& Grady, C. (2000). What Makes Clinical Research Ethical? JAMA, 283(20), 2701-2711.

Emanuel, E. J., Wendler, D., Killen, J., \& Grady, C. (2004). What makes clinical research in

developing countries ethical? The benchmarks of ethical research. The Journal of Infectious Diseases, 189(5), 930-7.

Erasmus, D. (2012). Video quality requirements for South African Sign Language communications over mobile phones. Unpublished MSc thesis. University of Cape Town, Department of Computer Science.

Hayes, G. R. (2011). The relationship of action research to human-computer interaction. $A C M$

Transactions on Computer-Human Interaction, 18(3), Article 15.

Hayes, G. R. (2012). Taking action in your research. Interactions, 19(4), 50-53.

Heeks, R. (1999). The Tyranny of Participation in Information Systems: Learning from Development Projects. In Development Informatics Working Paper Series (Paper 4). Manchester, UK: Institute for Development Policy and Management.

Heeks, R. (2002). Information Systems and Developing Countries: Failure, Success, and Local Improvisations. The Information Society, 18(2), 101-112.

Henney, A. J., \& Tucker, W. D. (2013). Information Protection in Video Relay Services. In 4th Annual Symposium on Computing for Development (DEV-4) (Article 24, 2 pages). Cape Town Dec 6-7; New York: ACM Press.

Hersh, M. A., \& Tucker, W. D. (2005). Ethics and mono-disciplinarity: Positivism, informed consent and informed participation. In P. Zftek (Ed.), 16th International Federation of Automatic Control World Congress (Vol. 16(1)). Prague Jul 4-8; Amsterdam: Elsevier.

Glaser, M. (2000). A field trial and evaluation of Telkom's Teldem terminal in a Deaf community in the Western Cape. In 2nd South African Telecommunication Networks and Applications Conference (SATNAC). Stellenbosch; Pretoria: Telkom.

Glaser, M., \& Aarons, D. (2002). A Deaf adult literacy collective. Stellenbosch Papers in Linguistics, 34, 1-18. 
Glaser, M., \& Tucker, W. D. (2004). Telecommunications bridging between Deaf and hearing users in South Africa. In Conference and Workshop on Assistive Technologies for Vision and Hearing Impairment (CVHI). Granada, Spain.

Glaser, M., Young, P., \& Porteous, L. (2005). An Information and Communication Technology (ICT) Needs Analysis and Training Programme for Deaf People. In 2oth International Congress on the Education of the Deaf (p. 231). Maastricht.

Glaser, M., \& Lorenzo, T. (2006). Developing literacy with Deaf adults. In B. Watermeyer, L. Swartz, T. Lorenzo, M. Schneider, \& M. Priestley (Eds.), Disability and social change: A South African agenda (pp. 192-205). Cape Town: HSRC Press.

Gurstein, M. (2010). The Ethical Responsibility of Academics in Community Informatics, 6(3).

Kam, M., Ramachandran, D., Raghavan, A., Chiu, J., Sahni, U., \& Canny, J. (2006). Practical

Considerations for Participatory Design with Rural School Children in Underdeveloped Regions: Early Reflections from the Field. In Interaction design and children (pp. 25-32). Tampere Jun 79; New York: ACM Press.

Kaplan, A. (1996). The Development Practitioners' Handbook (p. 128). London: Pluto Press.

Kemmis, S., \& McTaggart, R. (2000). Participatory Action Research. In N. K. Denzin \& Y. S. Lincoln (Eds.), Handbook of Qualitative Research (2nd ed., pp. 567-606). Thousand Oaks: Sage.

Lauwers, T., Kalra, N., Dias, M.B., Dewey, D. and Stepleton T. (2007). Iterative Design of A Braille Writing Tutor. In Proc. IEEE/ACM International Conference on Information and Communication Technologies and Development (ICTD2007). Bangalore Dec 15-16.

Looijesteijn, K. (2009). The design of a Deaf-to-hearing communication aid for South Africans. Unpublished MSc thesis; Delft University of Technology, Delft, Netherlands.

Ma, Z. Y., \& Tucker, W. D. (2007). Asynchronous video telephony for the Deaf. In D. Browne (Ed.), Southern African Telecommunication Networks and Applications Conference (SATNAC) (pp. 134-139). MauritiusSep 9-13; Pretoria: Telkom.

Ma, Z. Y., \& Tucker, W. D. (2008). Adapting x264 to asynchronous video telephony for the Deaf. In D. Browne (Ed.), Southern African Telecommunication Networks and Applications Conference (SATNAC) (pp. 127-132). Wild Coast Sun, Sep 7-10 ; Pretoria: Telkom. 
Ma, Z. Y. (2009). Semi-synchronous Video for Deaf Telephony with an Adapted Synchronous Codec. Unpublished MSc thesis. University of the Western Cape.

Mbulamwana, J. (2011). Technology and Deafness in Uganda: Accessibility and Appropriateness. Itupale Online Journal of African Studies, III.

McKay, J., \& Marshall, P. (2001). The dual imperatives of action research. Information Technology \& People, 14(1), 46-59.

Michener, V. J. (1998). The participatory approach: Contradiction and co-option in Burkina Faso. World Development, 26(12), 2105-2118.

Motlhabi, M. B., Glaser, M., Parker, M., \& Tucker, W. D. (2013a). SignSupport: A Limited

Communication Domain Mobile Aid for a Deaf patient at the Pharmacy. In R. Volkwyn (Ed.), Southern African Telecommunication Networks \& Applications Conference (pp. 173-178). Stellenbosch Sep 1-4; Pretoria: Telkom.

Motlhabi, M. B., Tucker, W. D., Parker, M., \& Glaser, M. (2013b). Improving Usability and

Correctness of a Mobile Tool to help a Deaf person with Pharmaceutical Instruction. In 4 th

Annual Symposium on Computing for Development (DEV-4) (Article 13, 10 pages). Cape Town Dec 6-7; New York: ACM Press.

Motlhabi, M. (2014). Usability and content verifcation of a mobile tool to help a Deaf person with pharmaceutical instruction. Unpublished MSc thesis, University of the Western Cape.

MRC. (2006). Guidelines on Ethics in Medical Research: General Principles. Medical Research Council. Retrieved Mar 11, 2014 http://www.sahealthinfo.org/ethics/.

Mutemwa, M., \& Tucker, W. D. (2010). A mobile Deaf-to-hearing communication aid for medical

diagnosis. In D. Browne (Ed.), Southern African Telecommunication Networks and Applications Conference (SATNAC) (pp. 379-384). Stellenbosch Sep 5-8; Pretoria: Telkom.

Pal, J., Ammari, T., Mahalingam, R., Alfaro, A. M. H., \& Lakshmanan, M. (2013). Marginality, aspiration and accessibility in ICTD. In Proc. Sixth International Conference on Information and Communication Technologies and Development Full Papers (ICTD '13), Volume 1 (pp. 68-78). Cape Town Dec 7-10; New York: ACM Press. 
Penton, J., Tucker, W. D., \& Glaser, M. (2002). Telgo323: an H.323 bridge for Deaf telephony. In Z. Miklos (Ed.), Southern African Telecommunication Networks and Applications Conference (SATNAC) (Vol. 2, pp. 309-313). Drakensberg Sep 1-4, South Africa: Telkom.

Power, M. R., \& Power, D. (2004). Everyone Here Speaks TXT: Deaf People Using SMS in Australia and the Rest of the World. Journal of Deaf Studies and Deaf Education, 9(3), 333-343.

Ramachandran, D., Kam, M., Chiu, J., Canny, J., \& Frankel, J. L. (2007). Social Dynamics of Early Stage Co-Design in Developing Regions. In Human Factors in Computing Systems (pp. 10871096). San Jose Apr 28 - May 3; New York: ACM Press.

Ramuhaheli, T. (2011). Gesture Based Interface for Asynchronous Video Communication for Deaf People in South Africa. Unpublished MSc thesis. University of Cape Town, Department of Computer Science.

Samant, D., Matter, R., \& Harniss, M. (2013). Realizing the potential of accessible ICTs in developing countries. Disability and Rehabilitation. Assistive Technology, 5(1), 11-20.

SAPC (2010). South African Pharmacy Council. Good Pharmacy Practice in South Africa. Printed By S.A. Council.

SignGenius, Disability Statistics: South Africa. SignGenius Sign Language Software. Available at http://www.signgenius.com/info-statistics.shtml. Accessed 10 March 2014.

Steneck, N., Mayer, T., \& Anderson, M. (2010). Singapore Statement on Research Integrity. In 2nd World Conference on Research Integrity. Singapore. See www.singaporestatement.org.

Sterling, S. R., \& Rangaswamy, N. (2010). Constructing Informed Consent in ICT4D Research. In ICTD 2010 (Article 46, 9 pages). London Dec 13-15; New York: ACM Press.

Stringer, E. (1997). Action Research: A handbook for practitioners. USA: Sage Publications.

Sun, T., \& Tucker, W. D. (2004). A Softbridge with carrier grade reliability using JAIN SLEE. In D. Browne (Ed.), Southern African Telecommunication Networks and Applications Conference (SATNAC) (Vol. 2, pp. 251-252). Stellenbosch Sep 6-8, South Africa: Telkom.

Susman, G. I., \& Evered, R. D. (1978). An Assessment of the Scientific Merits of Action Research. Administrative Science Quarterly, 23(4), 582-603. 
Tacchi, J., Slater, D., \& Hearn, G. (2003). Ethnographic Action Research. A User's Handbook Developed to Innovate and Research ICT Applications for Poverty Eradication. UNESCO.

Toyama, K., \& Ali, M. (2009). Computing for Global Development: Is it Computer Science Research ? ACM SIGCOMM Computer Communication Review, 39(5), 40-43.

Tucker, W. D., \& Blake, E. H. (2010). Abstractions for designing and evaluating communication bridges for people in developing regions. In First Annual Symposium on Computing for Development (DEV). Cambridge, New York: ACM Press.

Tucker, W. D., Glaser, M., \& Lewis, J. (2003). SoftBridge in action: the first Deaf telephony pilot. In Z. Miklos (Ed.), Southern African Telecommunication Networks and Applications Conference (SATNAC) (Vol. 2, pp. 293-294). George Sep 7-10, Pretoria: Telkom.

Wang, Y. Y., \& Tucker, W. D. (2010). Browser-based sign language communication. In D. Browne (Ed.), Southern African Telecommunication Networks and Applications Conference (SATNAC) (pp. 71-76). Stellenbosch Sep 5-8, Pretoria: Telkom.

Yi, L., \& Tucker, W. D. (2009). Automatic voice relay with open source Kiara. In D. Browne (Ed.), Southern African Telecommunication Networks and Applications Conference (SATNAC) (pp. 143-148). Swaziland Aug 30 - Sep 2; Pretoria: Telkom.

Zulu, T. A. Z., Le Roux, K. F., \& Glaser, M. (2005). A preliminary investigation into Text-To-Speech (TTS) software in a semi-automated relay service for Deaf telephony. The Division of Communication Sciences and Disorders, Department of Health and Rehabilitation Sciences, Faculty of Health Sciences. Unpublished thesis. University of Cape Town, Cape Town, South Africa. 


\section{List of acronyms}

$\mathrm{ACM}$

AT

BCS

CBCD

CIRN

CODA

$\mathrm{CoE}$

DCCT

DEAFSA

DEV

DPO

ECLD

HCI

ICDL

ICT

ICTD

ICT4D

IEEE-CS

IM

IRB

ITU

LMIC

MRC
Association of Computing Machinery

Assistive Technology

British Computer Society

Community-Based Co-Design

Community Informatics Research Network

Children of Deaf Adults

Centre of Excellence

Deaf Community of Cape Town

Deaf Federation of South Africa

Computing for DEVelopment, an ACM conference

Deaf People's Organisation (dedicated organisation similar to a

non-governmental or non-profit organisation)

European Computer Driver's License

Human Computer Interaction

International Computer Driver's License

Information and Communication Technology

ICT and Development, a conference (and flavour of research and

practise related to ICTD; see Sterling and Rangaswamy 2010)

ICT for Development

Institute of Electronic and Electrical Engineers Computer

Society

Instant Messaging

Institutional Review Board

International Telecommunications Union

Low and Middle Income Country

South African Medical Review Council 
MXit A popular South African mobile instant messaging tool that targeted low end feature phones, unlike WhatsApp being targeted to smart phones.

NRF National Research Foundation (South Africa)

PC Personal Computer

PD Participatory Design

RLE Resource Limited Environment

SANPAD South Africa Netherlands research Programme on Alternatives

in Development

SASL South African Sign Language

SIMBA Softbridge Instant Messaging Bridging Architecture

SMS Short Message Service, or mobile text

THRIP Technology and Human Resources for Industry Programme

TU Delft Delft University of Technology (Netherlands)

UCT University of Cape Town

UWC University of the Western Cape (also in Cape Town)

VoIP Voice over Internet Protocol

VRS Video Relay System 